\title{
Advantages and Limits of Remote Care and Stress Management Experienced by Mothers of Students with Specific Learning Disabilities During the Covid-19 Period.
}

\author{
Zhour Leqouider ${ }^{1}$, Zakaria Abidli², Bahae Ouali1, Latifa Kamal ${ }^{1}$, Joumana El Turk², Bouzekri Touri ${ }^{3}$, \\ Abdrrahim Khyati ${ }^{1}$.
}

\begin{abstract}
${ }^{1}$ Interdisciplinary Group of Didactics of Science \& Educational Sciences (GIDS\&SE-ENSC), The Multidisciplinary Laboratory in Sciences and Information Communication and Education Technology

(LAPSTICE), Faculty of Sciences Ben M'sik, Hassan II. University of Casablanca, Morocco,

${ }^{2}$ Faculty of Health Sciences, International University of Casablanca, Morocco,

LAPSTICE, Multidisciplinary laboratory of Sciences and Technologies of Information, Communication and Education), Hassan II. University of Casablanca, Morocco.
\end{abstract}

Received: May 30, 2021. Revised: November 16, 2021. Accepted: December 11, 2021. Published: January 3, 2022.

\begin{abstract}
These instructions give you guidelines for preparing papers. Use this document as a template if you are using Microsoft Word. Otherwise, use this document as an instruction set.. Define all symbols used in the abstract. Do not cite references in the abstract. Do not delete the blank line immediately above the abstract; it sets the footnote at the bottom of this column. Page margins are 1,78 cm top and down; $1,65 \mathrm{~cm}$ left and right. Each column width is $8,89 \mathrm{~cm}$ and the separation between the columns is $0,51 \mathrm{~cm}$.

Abstract-Introduction : The period of confinement due to the COVID-19 pandemic has harmful consequences on the psychological state of parents and their children, especially those with psychological or neurocognitive problems. The care of these children plays a primordial role in their development, particularly during the COVID-19 period. For this reason, our objective is to assess the state of stress among mothers of children with learning disabilities during the COVID-19 period in Morocco, as well as the support of these children.

Materials and methods : This is a cross-sectional study that was conducted during the period from April to June 2020. To realise it, we used a investigation form which contains three parts. To evaluate the state of stress in mothers, we used the "PSS10d" scale adapted to the Moroccan context. The target population is composed of mothers of children with learning disabilities who are being monitored by
\end{abstract}

Moroccan Association for Learning Disorders and Difficulties (MALDD) in Casablanca.

Results : During the period of confinement, only $13 \%$ $(n=15)$ of mothers reported that their children "Dys" had benefited from remote remediation by specialists According to the Odds Ratio calculation, the risk factors influencing the care of "Dys" children during this period of confinement are: lack of cooperation from the child (Odds Ratio= 16.8; IC95\%=[3.5-79]). 1]; P-value=0.001), the educational level of mothers (Odds Ratio= 9.4; IC95\% $=[2.4-35.7] ; P$-value $=0.001)$, the economic situation (Odds Ratio= 5.1; IC95\% $=[1.5-17.4] ; P$-value $=0.01)$ and technical problems (Odds Ratio $=5.1$; IC95\% $=[1.5-17.4]$; Pvalue $=0.01$ ).

Conclusion : According to our results, we noticed that the psychological state of the mothers is influenced by the remote care of the "Dys" children. For this the responsible authorities in Morocco must support this population.

Keywords-Remote support, learning disabilities, children, mothers, stress, COVID-19 period, Morocco. 


\section{INTRODUCTION}

$\mathrm{T}$ The world population is undergoing the most critical period of this millennium due to the emergence of the novel Severe Acute Respiratory Syndrome Coronavirus (SADRSCov-2) which is rapidly invading new territories around the world [1] . On January the 30th, 2020, the World Health Organization announced the coronavirus disease (COVID-19) outbreak as an international public health emergency. In Morocco, since the detection of the first real case of coronavirus (Covid-19) on March the second, 2020, to prevent the spread of the pandemic and preserve the health and safety of citizens, the Moroccan authorities decided to declare a health emergency and took a set of rapid and strict measures against Covid-19. All Moroccan cities were closed and the majority of industrial and commercial activities were forced to halt all activities until further notice. Likewise, citizens were asked not to leave their places of residence, except for particular reasons (purchase of basic necessities, medical consultations, etc.).

To this end, a series of preventive measures have been adopted by the ministries of education and family and solidarity concerning the closure of schools and medico-socialpsychological centers whose vocation is to welcome children with specific needs for diagnosis and treatment. This is particularly difficult for students with specific written language disorders (SLD). These neurobiological disorders disrupt the acquisition of written language, and affect individuals with normal intelligence, having benefited from adequate schooling in socio-economic conditions that facilitate learning [2]. Therefore, in the case of disorders that persist over time, the recovery pathway requires regular rehabilitation sessions and perseverance on the part of the parents and the therapists responsible for the care. Except that, the guarantee of effective health security requires social distancing vis-à-vis medical and paramedical staff and accompanying persons.

Indeed, the adoption of these measures exposes these young schoolchildren to several problems, including the halt face-toface lessons and termination of rehabilitation and remediation sessions. According to several scientific studies, the interruption of these care sessions has considerably worsened the pathological state of these students and the psychological state of their parents, especially the mothers [3]. Having a child with SLD or psychological problems is stressful for parents [45], In addition to financial problems; they are subject to emotional pressures such as shame or feelings of guilt, which can create a feeling of helplessness in them [4-5-6]. Be that as it may, the stress rate of parents has even further increased during this pandemic following the need to comply with health restriction measures, among other things [7]. Moreover, under similar circumstances, such as geographic distance, lack of professionals who can encourage practitioners to try other alternatives to carry on their sessions [8], such as tele-speech therapy [9-10]. Computer-assisted cognitive remediation [1112-13], Telemedicine [14-10]. Hence, these initiatives are motivated by the potential offered by these novel technological tools and communicative means [ 15-16]. The advantages of using novel assessment tools at a distance in health fields have been the subject of several studies [17-18] in [10] particular, in the fields of rehabilitation and remediation, be it in speech therapy [8-19] or in psychology [20-21] (it is what allowed the field to develop further).

In this regard, (Lanaud, et al., 2016) reported that results from several studies and experiments carried out in the United States and Australia [22] were satisfactory. Particularly in the fields of communication [23], stuttering [24], oral language disorders in children [25], disorders of neurological origin [26] In the same context, (Lanaud, et all., 2016) explains that the disorders of written and oral language, seem to be more suitable for remote management of subjects aged between 12 and 17 years. To further endorse this claim, we can cite a research whose results are promising, carried out as part of a doctoral thesis which looked at the possibilities offered by new technologies during the implementation of a platform whose focal aim is to develop applications for the diagnosis and management of dyslexia [27].

So according to our surveys on major scientific research bases like Scopus and Pub Med, no study has been carried out on the psychological state of mothers of children with learning disabilities, as well as the methods employed for their care during this pandemic. The present study has 2 objectives: 1 . to assess the state of stress in mothers of children with learning disabilities during the COVID-19 period in Morocco, 2. to assess the limits and advantages of taking remote load (PECD) of children with SLD.

\section{METHOD}

The present study was carried out following the establishment of a remote rehabilitation system by the Moroccan Association for Learning Disorders and Difficulties (MALDD) to avoid the interruption of support sessions for the benefit of students with SLD during lockdown. Accordingly, this is a cross-sectional observatory study, carried out between April and June 2020 and which consisted of a live remote intervention. The meeting between the students and the therapists is done via one of the following videoconferencing programs: Skype, Zoom or Google Meet according to their availability.

For data collection, we developed a self-administered survey sheet comprising 16 items, divided into three parts. The first part deals with socio-demographic information in relation to mothers and their children with SLD; a second part concerns data relating to specific learning disabilities, a third part assesses the advantages and limitations of remote care children with SLD during the COVID-19 period. Finally, a fourth part consists of the stress measurement scale "Perceived Stress Scale" translated into the Moroccan Arabic dialect «PSS10d » [28]. To better understand the items of the scale, two stages of translation and back-translation were undertaken by linguists.

Data collection was carried out by specialists in psychology and neuropsychology working in the medico-socialpsychological center of MALDD in Casablanca. 
The target population is made up of mothers of children diagnosed in a longitudinal epidemiological study as having specific learning disabilities. The subjects of our sub-sample are taken care of within the medico-socio-psycho-pedagogical center managed by MALDD in: speech therapy, psychomotor skills, psychology and neuropsychology. Excluded from the study are mothers whose children consult for a first diagnostic assessment, and therefore who have never had face-to-face contact with rehabilitation professionals before the implementation of the PECD system.

Psychometrically, we calculated Cronbach's alpha coefficient, an alpha between 0.6 and 0.8 is acceptable for an exploratory study [29]. To determine the associations between the variables studied, we carried out bivariate analyzes (the chisquare test and the student's $t$ test). Associations between risk factors and the dependent variable (management of children with SLD during quarantine) are presented as odds ratios (OR) and $95 \%$ CI. The significance level was set at P-value $\leq 0.05$. These analyzes are performed using SPSS (Statistical Package for the Social Sciences) software version 21. Ethically, we respected the confidentiality and anonymity of the participants.

\section{RESULTS}

During the study period, 119 mothers agreed to participate in this survey, they have an average age of $31.5 \pm 5.6$ years, with a minimum of 25 years and a maximum of 40 years. With regards to the intellectual level, $64 \%$ of the participants were at the university level. Regarding the marital situation, $82 \%$ of the mothers are married. Economically, $51 \%$ of the participants had an average economic situation. In terms of number of children with SLD we found that $86 \%$ of mothers had more than one child with specific learning disabilities with an average of $1.1 \pm$ 0.3 children with SLD per mother.
Tableau 1 : Socio-economic parameters of the participants in this study.

\begin{tabular}{|l|l|l|}
\hline \multicolumn{1}{|c|}{ Variable } & Efficacy & Percentage \\
\hline Educational Level & 76 & $64 \%$ \\
\hline Schooled & 43 & $36 \%$ \\
\hline Illiterate & 97 & $82 \%$ \\
\hline Marital situation & 22 & $18 \%$ \\
\hline Married & 21 \\
\hline Divorced & 61 & $18 \%$ \\
\hline Socio-economic level & 37 & $51 \%$ \\
\hline High & $31 \%$ \\
\hline Middle & 17 \\
\hline Low & 102 & $14 \%$ \\
\hline Number of "Dys" children by mothers & $86 \%$ \\
\hline One dys child & \multicolumn{2}{|l|}{$31.5 \pm 5.6$ years } \\
\hline More than one dys child & $1.1 \pm 0.3$ \\
\hline Mean and standard deviation \\
\hline Age & \\
\hline Number of children &
\end{tabular}

In relation to the nature of the learning disabilities, we noted that $97 \%(n=116)$ of children are dyslexics, followed by $94 \%$ dysorthographics $(\mathrm{n}=112)$. Likewise, we noted that $74 \%(\mathrm{n}=$ $88)$ of students are dysgraphic and $39 \%(n=47)$ of the children have dyscalculia. Low percentages were observed for dyspraxics and dysphasics, respectively $5 \%(\mathrm{n}=6)$ and $3 \%(\mathrm{n}$ $=3$ ) (Figure 1$)$. Further, only $3 \%(n=4)$ of children with SLD had a single learning disability. The sex ratio (male / female) is in favor of males with $1.8(\mathrm{P}$-value $=0.05)$, i.e. a percentage of $66 \%(n=79)$ boys and $34 \%(n=40)$ girls. The average age of children with SLD is 11 years old. 


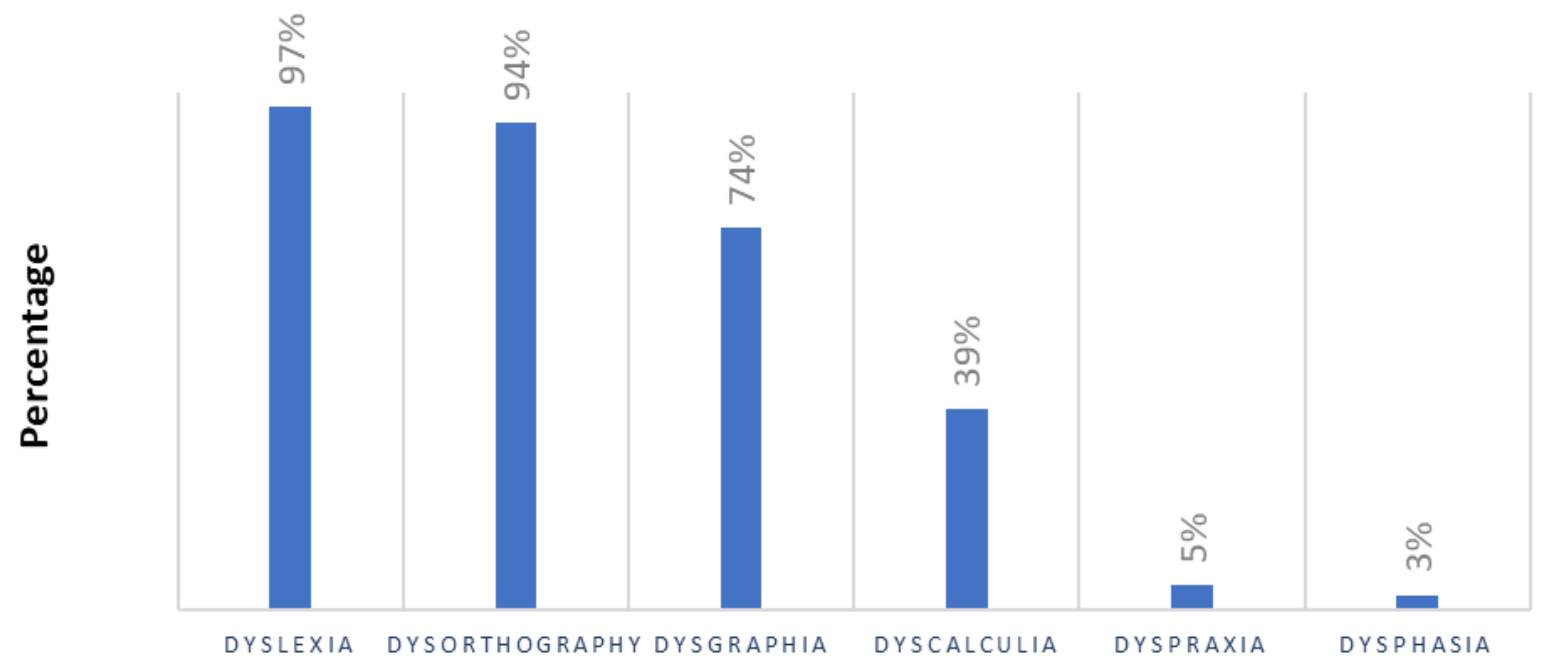

\section{Learning disability type}

Figure 1. Breakdown by type of learning disability

\section{Caring for Dyslexic children during the COVID-19 period}

During quarantine, $13 \%(n=15)$ of the mothers surveyed noted that their children with SLD were able to benefit from remote care by speech therapists and psychologists (figure 2), of which $87 \%(\mathrm{n}=13)$ had undergone speech therapy and $67 \%$ $(\mathrm{n}=10)$ psychological remediation. In terms of frequency, $60 \%$ $(\mathrm{n}=9)$ of mothers reported that their children had performed 2 sessions per week. Concerning the quality of care, $93 \%(n=14)$ of mothers report that the quality was rather average. Additionally, $73 \%(\mathrm{n}=11)$ of children with SLD were reported to have low interactivity during the distance rehabilitation sessions. All mothers whose children had benefited from a PECD that the progress in terms of rehabilitation was rather average. In our study, $70 \%(n=10)$ of mothers declared that the factors linked to the costs generated by travel expenses, flexibility over time, and respecting the frequency of rehabilitation sessions, are among the main advantages of PECD children with TSALE,

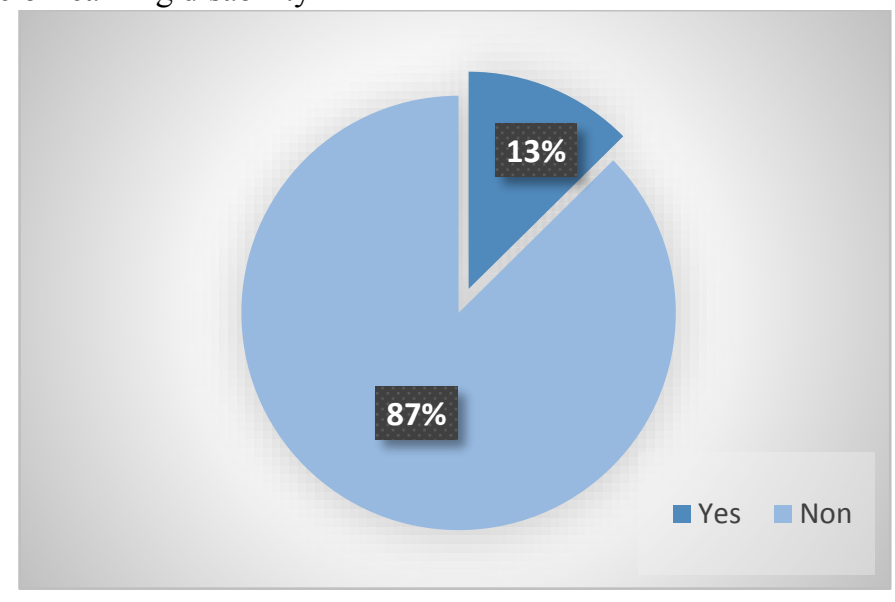

Figure 2. Distribution of mothers according to the care of their "Dys" children during the confinement period ***: The difference is highly significant between the two modalities $(\mathrm{P}$-value $<0.0005$ 
Factors inhibiting the management of "Dys" children during the COVID-19 period

During quarantine (Covid Lockdown period) , $87 \%$ or $(\mathrm{n}=$ 104) of the children with SLD in our sample, had not benefited from PECD (Figure 1). In order to highlight the risk factors influencing PECD, we studied the effects of the following elements:

1. Access to technological tools, and the internet.

2. Socioeconomic profiles of the mothers.

3. Educational level of the mothers

4. Lack of collaboration of the children during the rehabilitation sessions

5. The availability of mothers to accompany their children during PECD.

Table 2. Sociodemographic parameters of the participants in this study

\begin{tabular}{|c|c|c|c|c|c|}
\hline \multirow[t]{2}{*}{ Variable } & \multicolumn{2}{|c|}{$\begin{array}{l}\text { Support obtained during } \\
\text { lockdown }\end{array}$} & \multirow[t]{2}{*}{$\begin{array}{l}\text { Odds } \\
\text { Ratio }\end{array}$} & \multirow[t]{2}{*}{ IC $95 \%$} & \multirow[t]{2}{*}{ P-value } \\
\hline & No $(\%)$ & Yes $(\%)$ & & & \\
\hline \multicolumn{6}{|c|}{ Socio-economic level of the mothers } \\
\hline Yes & $11(73 \%)$ & $36(35 \%)$ & \multirow{2}{*}{5.1} & {$[1.5-$} & \multirow{2}{*}{$0.01 * *$} \\
\hline No & $4(27 \%)$ & $68(65 \%)$ & & $17.4]$ & \\
\hline \multicolumn{6}{|c|}{ Use of digital tools } \\
\hline Yes & $10(66 \%)$ & $34(33 \%)$ & \multirow{2}{*}{4.1} & \multirow{2}{*}[1.3-13]{} & \multirow{2}{*}{$0.01 * *$} \\
\hline No & $5(33 \%)$ & $70(67 \%)$ & & & \\
\hline \multicolumn{6}{|c|}{ Educational level of the mothers } \\
\hline Illiterate & $12(80 \%)$ & $31(30 \%)$ & \multirow{2}{*}{9.4} & {$[2.4-$} & \multirow{2}{*}{$0.001 * * *$} \\
\hline Schooled & $3(20 \%)$ & $73(70 \%)$ & & $35.7]$ & \\
\hline \multicolumn{6}{|c|}{$\begin{array}{l}\text { Availability of mothers to accompany their children during } \\
\text { the PECD. }\end{array}$} \\
\hline Yes & $7(47 \%)$ & $38(37 \%)$ & \multirow{2}{*}{1.5} & {$[0.5-$} & \multirow{2}{*}{ N.S } \\
\hline No & $8(53 \%)$ & $66(63 \%)$ & & 4.5] & \\
\hline \multicolumn{6}{|c|}{$\begin{array}{l}\text { Children's lack of collaboration during rehabilitation } \\
\text { sessions }\end{array}$} \\
\hline Yes & $13(87 \%)$ & $29(28 \%)$ & \multirow{2}{*}{16.8} & {$[3.5-$} & \multirow{2}{*}{$0.001 * * *$} \\
\hline No & $2(13 \%)$ & $75(72 \%)$ & & 79.1] & \\
\hline
\end{tabular}

N.S: Not significant; *: Significant at the 0.05 level (bilateral); ** Significant at the 0.01 level (bilateral); ***: Significant at the 0.001 level (bilateral) ; CI: Confidence Interval.

According to the calculation of the Odds Ratio, we noted that the risk factors that influence the PECD of "Dys" children during lockdown period are the following:

- Childrens' lack of collaboration during rehabilitation sessions (Odds Ratio $=16.8 ; 95 \% \mathrm{CI}=[3.5-79.1]$; P-value $=$ $0.001)$,

- Educational level of mothers (Odds Ratio = 9.4; 95\% CI = [2.4-35.7]; P-value = 0.001);

- Socio-economic level of mothers (Odds Ratio $=5.1 ; 95 \%$ $\mathrm{CI}=[1.5-17.4] ; \mathrm{P}$-value $=0.01)$;

- Use of digital tools (Odds Ratio $=5.1 ; 95 \% \mathrm{CI}=[1.5-17.4]$; $\mathrm{P}$-value $=0.01$ ).
Assessment of the stress level of the mothers during the lockdown period:

To assess the stress level of the mothers who participated in this study, we used the PSS10 scale translated into the Moroccan dialect. For a better reliability of the scale items we calculated the Cronbach index. The latter was satisfactory with alpha $=0.8$. Regarding the PSS10 scores, an average of $18.9 \pm$ 1.1 was reported in the mothers of our study, the high scores were observed in the mothers of children with SLD, who did not benefit from PECD during lockdown, with 20.1 \pm 1.1 (Table 3 ). Likewise, according to the student's t test, we noted a highly significant association between the scores of mothers in the stress scale and management of children with SLD during (Page 9) lockdown (P-valu $<0.001)$. If we take into account the socioeconomic level, the student's t test revealed that mothers with a disadvantaged socio-economic level were the most stressed (Pvalu $\leq 0.001$ ) (Table 3). Further, the same test did not yield a significant association between the number of children with SLD per mother. However, a slightly higher score in mothers with more than one child with SLD was noted, with $19.1 \pm 1.1$ (Table 3).

Table 3. Associations of PSS10 scores translated into Moroccan dialect with the economic level of the mothers, the number of "Dys" children and the care of "Dys" children during the confinement period.

\begin{tabular}{|c|c|c|c|}
\hline & Score & $\mathbf{t}$ & P-value \\
\hline \multicolumn{4}{|c|}{ Support for "Dys" children during lockdown } \\
\hline Yes & $18.8 \pm 1.04$ & \multirow{2}{*}{4.1} & \multirow{2}{*}{$0.001 * * *$} \\
\hline No & $20.1 \pm 1.1$ & & \\
\hline \multicolumn{4}{|c|}{ Socio-economic level of the mothers } \\
\hline Medium or high & $18.3 \pm 0.8$ & \multirow{2}{*}{10.1} & \multirow{2}{*}{$0.001 * * *$} \\
\hline Low & $20.4 \pm 1.4$ & & \\
\hline \multicolumn{4}{|c|}{ Number of "Dys" children by mothers } \\
\hline A"Dys" child & $18.6 \pm 1.1$ & \multirow[b]{2}{*}{-1.4} & \multirow[b]{2}{*}{$0.270^{\mathrm{n} . \mathrm{s}}$} \\
\hline $\begin{array}{l}\text { More than one "Dys" } \\
\text { child }\end{array}$ & $19.1 \pm 1.1$ & & \\
\hline
\end{tabular}

N.S: Not significant; *: Significant at the 0.05 level (bilateral); ** Significant at the 0.01 level (bilateral); ***: Significant at the 0.001 level (bilateral).

\section{DISCUSSION}

The average age of mothers our study is of the order (evaluated to be around) of 31.5 years, a result consistent with the figures put forward by the Moroccan HCP which attests that the average age of marriage in Morocco is of the order of 26.6 years [30]. Thus, having a child aged 11 at an age of 31.6 is quite normal. The average age of the children with SLD in our study is determined by the educational level of the students supported within the association (5th and 6th year of primary school). The socioeconomic profile of the mothers in our sample, which is considered high in $18 \%$ of cases, average in $51 \%$ of cases and 
low for the remaining $31 \%$, is comparable to that of the population that usually goes to the association. Regarding the sex ratio, a clear predominance of the male sex is found in our sample. Despite the ongoing debate on this issue, our results accord with authors who argue for the association between SLD and male sex [31-32]. Regarding the distribution of children by type of learning disability, our results corroborate results reported by other authors, in particular those who explain that the incidence of dyslexia is higher compared to other learning disabilities [33]. Moreover, this dysfunction is rarely isolated [34], it is accompanied by other disorders [35] the most frequent one being dysorthography [36].

The quantitative analysis showed that only $13 \%$ of the mothers questioned reported that their children with SLD had received remote rehabilitation by specialists. However, the risk factors influencing PECD, according to the Odds Ratio, in decreasing order, are the following: the childrens' lack of collaboration during remote sessions, the mothers' level of education, the parents' socioeconomic situation, and lastly the technical problems related to the connection and / or good knowledge of computer use.

Similarly, the lack of collaboration of children with SLD constitutes a risk factor that impacted the implementation of PECD during lockdown, the results are consistent with studies confirming that failures experienced by students with SLD are mainly due to their disinvestment and lack of inhibition during their distance rehabilitation sessions [9]. Due mainly to their cognitive impairments and unfavorable life conditions because of their impairments. In addition, in normal times, these pupils suffer from a lack of concentration and attention [32], therefore the hypothesis that one can advance to explain this situation is to posit that children are more easily tempted by online games and videos. during distance rehabilitation sessions. Likewise, as was reported by [15], the absence of face-to-face contact between the practitioner and the patient implies the accompaniment of a third person, something which has been confirmed by (Dufournier, 2017) who considers that the supervision of children during PECD aims to maintain their attention. However, if we take into account the other risk factors that contributed to the suspension of the PECD, such as the socioeconomic profile and the level of education of the accompanying persons (in our case, the mothers), several authors consider that these two factors may have a negative impact on certain areas of childrens' development [35]). As the lecture [36]) and academic success [37], However, these comments lead us to ask the following question: Could it be that quality of support during remote rehabilitation sessions could not guarantee better collaboration of children during distance rehabilitation? Moreover, does the establishment of the PECD necessitate a good command of computers, cameras, microphone, and videoconferencing software? 12,4 . However, a disadvantaged socioeconomic profile can create inequalities in the acquisition and use of novel communication technologies 14 hence hindering access to remote care. Moreover, as evidenced by mothers whose children benefited from a PECD, the quality and progress in terms of rehabilitation was predominantly average. Indeed, the arguments that can be advanced to explicate this finding is the consideration that this project constituted an emergency solution in a lockdown period caused by covid-19. Indeed, the implementation of this device was an emergency solution in a particular context, inherent to the pandemic period, therefore and as explained [37] the users did not have enough experience when handling PECD tools. However, the results relating to the costs generated by travel expenses, the flexibility in time for the organization of the sessions and the respect of the regular rhythm of the rehabilitation were advantages very appreciated by the mothers surveyed. Regarding these advantages, our comments corroborate the findings reported by other researchers [38-3940-41]. Further, the stress rate perceived by mothers is significantly influenced by the socioeconomic profile of mothers, and suspension of rehabilitation sessions (P-value $<0.001$ ). Thus, if we consider our analysis of the risk factors that impacted PECD, a causal relationship is found between these two factors. In a normal setting, parents of children with SLD are exposed to ongoing stress and high levels of frustration and dissatisfaction [40-41]. Hence, the current health crisis only further worsens this situation [42-43], by adding other constraints pertaining the mothers' disadvantaged socioeconomic profiles and their lower levels of education, could not guarantee access to a PECD for their children by providing them with effective support. Notwithstanding, PECD could help them overcome their stress during this pandemic. To further illustrate these remarks, we cite the conclusions of certain studies, which explain that teleconsultation during lockdown is positively perceived by parents. Moreover, these interventions could constitute an alternative to face-to-face care and access to appropriate care [44-45-46]. However, confidentiality measures must be respected, to preserve the clinical, ethical and psychological aspect of the therapistpatient relationship1, pour préserver l'aspect clinique, éthique et psychologique de la relation thérapeute-patient. However, our study is not without its limitations, thus in no case can these results be generalized to a larger population seeing that the percentage of the population having benefited from remote care is limited to $15 \%$. It would have been interesting to carry out exploratory studies on the acquisition and / or mastery of computer tools before starting this study to guarantee access of a wider population to PECD and subsequently to conduct the experiment on a larger sample.

For the data collection, we were limited to mothers, when we should have included the therapists who carried out the PECD as well to ensure an objective assessment of the quality of the remote sessions, and to have a professional viewpoint of the factors that hindered the PECD. It would have also be relevant to set up an awareness-raising and training program for the benefit of accompanying persons, before the implementation of the PECD, on the methods of supervision, and of support required to ensure a good collaboration of the children during PECD. Nevertheless, despite these limitations, the present study contributes to the the scientific literature regarding remote rehabilitation of SLD. Subsequently, although the rate of subjects having benefited from a PECD was very low (15\%), some disadvantages and advantages of the PECD were noted. In this context, the present study can form the basis for the 
establishment of a more efficient device for the online rehabilitation of children with SLD in remote areas.

\section{CONCLUSION}

To conclude, this study shed some light on a device tailored specifically for the remote management of specific learning disabilities of the written language "dyslexia", this mode of rehabilitation constitutes a reliable alternative solution that is suitable for patients who, due to remoteness, lack of rehabilitation professionals, or other conditions (natural disasters, health crises) cannot access face-to-face rehabilitation sessions. However, and as other researchers posited, the establishment and success of this care method is based upon digital literacy a very good internet connection which are all essential for remote rehabilitation, along with the building of support workers' capacities through training and awareness programs.

\section{REFERENCE}

[1] D.S Jones, "History in a crisis - lessons for covid-19", N Engl J Med, vol.30, pp.1681-1683. Doi: 10.1056/NEJMp2004361. Epub 2020 Mar 12. PMID: 32163699 .

[2] World Health Organization. International Statistical Classification of Diseases and Related Health Problems (2008). Available https://icd.who.int/browse10/Content/statichtml/ICD10Volum e2_fr_2008.pdf.

[3] N. Lebkiri, Z. Abidli, S. Jadda, A. Mokhtari, A. Soulaymani. "Impact of containment type on Covid-19 propagation in Morocco using the SIR model".Bangladesh Journal of Medical Science, vol. 19, pp. 58- 65, 2020. DOI: https://doi.org/10.3329/bjms.v19i0.48167.

[4] F. Awat, N. Badroddin, S. Aseih, C. Maryam, H. Rezvan. "Parenting stress among mothers of children with different physical, mental, and psychological problems". J Res Med Sci, vol. 19, pp. 145-152, 2014.

[5] RE. Clark, RE. Drake. "Expenditures of time and money by families of people with severe mental illness and substance use disorders". Community Ment Health J, vol. 30, pp.145-63, 1997. doi: 10.1007/BF02188626. PMID: 8013212.

[6] M. Ostberg, B. Hagekull. "A structural modeling approach to the understanding of parenting stress". J Clin Child Psychol, vol.29, pp. 615-25, 2000. doi: 10.1207/S15374424JCCP2904_13. PMID: 11126638.

[7] H. Preuss, K. Capito, RL. van Eickels, M. Zemp, DR. Kolar. "Cognitive reappraisal and self-compassion as emotion regulation strategies for parents during COVID-19: An onlinerandomized controlled trial". Internet Interv, 2021 Apr 6; 24:100388. doi: 10.1016/j.invent.2021.100388.
[8] M. Lachenaud, E. Laflaquière. "Des ressources technologiques pour aider le suivi orthophonique à distance des troubles articulatoires des enfants, dont ceux porteurs de trisomie 21", Mémoire CCO, Université Lyon, 2016.

[9] D. Pascaline."De la formation ouverte à distance à la rééducation orthophonique à distance : vers une nouvelle approche enrichie de l'orthophonie ? “. Ph.D , Université Lumière Lyon 2, 2017

[10] R. Géraldine, “Télé orthophonie : l'éloignement met-il à distance la relation thérapeutique ? Médecine humaine et pathologie“" Ph.D, Faculté de Médecine, École d'orthophonie, Nice, 2016.

[11] B. Forgeot , J.M, Guilé , D. Cohen , "Une thérapie émergente du trouble déficitaire de l'attention : la remédiation cognitive assistée par ordinateur", Perspectives Psy,50(1):6977,2011 .

[12] M. Bader. (2014, Sptember). "Les remédiations cognitives entre rééducation et thérapie du TDAH“. Available: https://www.jdpsychologues.fr/article/la-remediationcognitive-une-nouvelle-approche-du-tdah.

[13] B. Forgeot , J.M, Guilé, D. Cohen. "Une thérapie émergente du trouble déficitaire de l'attention : la remédiation cognitive assistée par ordinateur".Perspectives Psy,50(1):6977,2011 .

[14] J. Portnoy, M.Waller, T. Elliott, T. "Telemedicine in the Era of COVID-19“. The Journal of Allergy and Clinical Immunology: In Practice, vol. 8, pp. 1489-1491, 2020.

[15] M. Lachenaud, E. Laflaquière, "Des ressources technologiques pour aider le suivi orthophonique à distance des troubles articulatoires des enfants, dont ceux porteurs de trisomie 21, Mémoire CCO, Université Lyon 1, 2016.

[16] L. Payne, H. Flannery, C. Kambakara, Gedara, X. Daniilidi,M. Hitchcock,D. Lambert, C. Taylor, D. Christie. "Business as usual? Psychological support at a distance". Clin Child Psychol Psychiatry, 25(3):672-686,2020.

[17] S. Bacha, O. Taouali, N. Liouane, "A Mammographic Images Classification Technique via the Gaussian Radial Basis Kernel ELM and KPCA“. Int. J. of Applied Mathematics, Computational Science and Systems Engineering, 2:92-98, 2020.

[18] L. Payne, H. Flannery, C. Kambakara, Gedara, X. "Daniilidi,M. Hitchcock,D. Lambert, C. Taylor, D. Christie. Business as usual? Psychological support at a distance". Clin Child Psychol Psychiatry, 25(3):672-686,2020.

[19] D. Baril, 'La thérapie à distance réussit aussi bien qu'en face à face“, Ph.D. Université Nice Sophia Antipolis ,Faculté de Médecine, Ecole d'Orthophonie, 2016. 
[20] D. Samama, C.Voisin, O. Komano,R. Jouvent, Pour une remédiation à distance. Dans N.Franck, Remédiation cognitive. Issy-les-Moulineaux : Elsevier Masson, 2017, pp.344-348.

[21] L. Payne, H. Flannery, C. Kambakara, Gedara, X. Daniilidi,M. Hitchcock,D. Lambert, C. Taylor, D. Christie. "Business as usual? Psychological support at a distance". Clin Child Psychol Psychiatry, 25(3):672-686,2020.

[22] Molini-Avejonas DR, Rondon-Melo S, Amato CA, Samelli AG. "A systematic review of the use of telehealth in speech, language and hearing sciences". J Telemed Telecare, 21(7):367-376, 2015.

[23] V. Styles, V. "Service users' acceptability of videoconferencing as a form of service delivery". Journal of Telemedicine and Telecare, 14(8):415-420, 2008.

[24] C. Sicotte, P. Lehoux, J. Fortier-blanc, Y. Leblanc, "Feasibility and outcome evaluation of a telemedicine application in speech-language pathology", Journal of Telemedicine and Telecare, 9(5):253-258, 2003.

[25] S. Grogan-Johnson, RM. Gabel, J. Taylor, LE. Rowan, R . Alvares, J. Schenker. A pilot exploration of speech sound disorder intervention delivered by telehealth to school-age children. Int J Telerehabil,3 (1):31-42, 2011.

[26] A. Georgeadis, D. Brennan, L. Barker, C. Baron, "Telerehabilitation and its effect on story retelling by adults with neurogenic communication disorders". Aphasiology, $18(5-7): 639-652,2004$.

[27] G. Geoffrey. "Une approche logicielle du traitement de la dyslexie Étude de modèles et applications" $\mathrm{Ph} . \mathrm{D}$, Université Blaise Pascal - Clermont-Ferrand II, Université Blaise Pascal Clermont-Ferrand II, 2015.

[28] D. Ben Loubir, Z. Serhier, N. Otmani, S. Housbane, N. Ait Mouddene, M. Agoub, M. Bennani Othmani. "Perceived stress: validation of the translation of a stress measuring scale in Moroccan dialect“, Pan Afr Med J. 2015; 21: 280.

[29] DMSP Research Centre. (2003). Proposition of a contextualizedscale of measurementteam learning: An ExploratoryAnalysis. Université de Paris-Dauphine, Paris, France.2003.Available

:https://basepub.dauphine.fr/bitstream/handle/123456789/4299 /CR321.pdf\%3Bsequence\%3D1.

[30] High Commission for Planning. General Census of Population and Housing 2004. Available: https://www.hcp.ma/Mariage-et-divorce-de-la-femmemarocaine-Tendances-d-evolution_a1261.html mariage et divorce de la femme marocaine : tendances d'évolution
[31] M. Rutter, A. Caspi, D. Fergusson, LJ. Horwood, R. Goodman, B. Maughan, TE. Moffitt, H. Meltzer, Carroll J. "Sex differences in developmental reading disability: new findings from 4 epidemiological studies", JAMA, 291(16):2007, 2004.

[32] C. Billard, B. Ducot, F. Pinton, D.Coste-Zeitoun, S.Picard, J. Warszawski. BREV, une batterie d'évaluation des fonctions cognitives : validation dans les troubles des apprentissages, Archives de Pédiatrie, 13(1):23-31,2006.

[33] M. Habib. La constellation des dys: Bases neurologiques de l'apprentissage et de ses troubles, 2e Édition, Paris: De Boeck-Solal, pp:368, 2018.

[34] M. Habib. La dyslexie à livre ouvert. Marseille: Résodys. 2003.

[35] H. Andrea, J. Marianne, R. Jean-Yves. Difficultés associées et scolarisation des enfants dyslexiques. La nouvelle revue de l'adaptation et de la scolarisation, Éd. de l'INSHEA, 2017, pp.168- 181.

[36] M. Habib, B. Joly-Pottuz. Dyslexie, du diagnostic à la thérapeutique : un état des lieux. Revue de Neuropsychologie, 18(4), 247-325, 2008.

[37] NN. Al Awaji, AA. Almudaiheem, EM. Mortada, Assessment of caregivers' perspectives regarding speechlanguage services in Saudi Arabia during COVID-19. PLoS One, 22;16(6):e0253441, 2021.

[38] Berman A. Parenting learning-disabled children. J Clin Child Psychol (1979) 8:245 9.10.1080/15374417909532930

[39] Nalavany BA, Carawan LW. Perceived family support and self-esteem: the mediational role of emotional experience in adults with dyslexia. Dyslexia. 2012; 18 (1):58-74. doi:10.1002/dys.143

[40] Al-Yagon M. Children at risk for learning disorders: multiple perspectives. J Learn Disabil. 2003; 36 (4):318-335. doi: $10.1177 / 00222194030360040401$

[41] Antshel KM, Joseph GR. Maternal stress in non-verbal learning disorder: a comparison with reading disorder. J Learn Disabil. 2006 ; 39(3) :194-205. Doi : 10.1177/00222194060390030101 ;

[42] E. Parizel, Philippe. M, W René . «La télémédecine en questions », Études, 419(11):461-472.2013.

[43] LIVES Impact,Tettamanti M, Darwiche J. (June, 2020). Vulnérabilité familiale en période de confinement: quelles pistes de résilience?. Available: https://www.centrelives.ch/sites/default/files/inline-

files/LIVES\%20IMPACT_Special\%20issue\%202_July_2020 \%20_FR.pdf 
[44] Bobo E, Lin L, Acquaviva E, et al. Comment les enfants et adolescents avec le trouble déficit d'attention/hyperactivité (TDAH) vivent-ils le confinement durant la pandémie COVID19 ? [How do children and adolescents with Attention Deficit Hyperactivity Disorder (ADHD) experience lockdown during the COVID-19 outbreak?]. Encephale. 2020; 46(3S):S85-S92. doi:10.1016/j.encep.2020.05.011

[45] Flodgren G., Rachas A., Farmer A.J. Interactive telemedicine: effects on professional practice and health care outcomes. Cochrane Database Syst Rev. 2015;9:CD002098

[46] Fairchild R.M., Ferng-Kuo S.-F., Rahmouni H. Telehealth increases access to care for children dealing with suicidality, depression, and anxiety in rural emergency departments. Telemed J E-Health. 2020 DOI: 10.1089/tmj.2019.0253.

\section{Creative Commons Attribution License 4.0 (Attribution 4.0 International, CC BY 4.0)}

This article is published under the terms of the Creative Commons Attribution License 4.0

https://creativecommons.org/licenses/by/4.0/deed.en US 